\title{
IDENTIFICACIÓN DEL GEN MECA POR PCR Y PCR-RT DE STAPHYLOCOCCUS AUREUS
}

\author{
Identification of the mecA gene by $P C R$ and $P C R-R T$ of Staphylococcus aureus
}

EPISTEMUS

ISSN: 2007-8196 (electrónico)

ISSN: 2007-4530 (impresa)

Patricia Palafox Rivera ${ }^{1}$

Michel Palafox Félix ${ }^{2}$

Jorge Alberto Peralta Mendoza 3

Recibido: 12 de septiembre de 2016

Aceptado: 30 de noviembre del 2016

Autor de Correspondencia:

Lic. Tecnología de alimentos Patricia Palafox Rivera

Correo: patricia.palafox.mc18@estudiantes.ciad.mx

\section{Resumen}

En la actualidad, la aplicación de técnicas más eficientes que contribuyan a la identificación de patógenos como Staphylococcus aureus de forma más rápida se ha vuelto esencial debido a que estos patógenos forman parte de la principal problemática en infecciones nosocomiales. La persistencia del problema se debe a que estos patógenos han desarrollado resistencia ante las amenazas del medio ambiente. El uso excesivo de sanitizantes y antibióticos como la meticilina son los causantes de la resistencia que en este caso proviene del gen mecA. La identificación de este gen es determinante para diferenciar a las cepas resistentes y no resistentes. Sin embargo, tomando en cuenta que los procesos tradicionales para identificación de este patógeno suelen ser muy tardados, se aplican técnicas como el PCR, por su eficacia y eficiencia. No obstante, técnicas como el PCR$\mathrm{RT}$ poseen mejoras que aportan cierta ventaja en comparación con su predecesor.

Palabras clave: Staphylococcus aureus, SARM, PCR, PCR-RT

\begin{abstract}
At present, the application of more efficient techniques that contribute to the identification of pathogens such as Staphylococcus aureus more quickly has become essential because these pathogens are part of the main problem in nosocomial infections. The persistence of the problem is due to the fact that these pathogens have developed resistance to environmental threats. The excessive use of sanitizers and antibiotics such as methicillin are the cause of the resistance that in this case comes from the mecA gene. The identification of this gene is crucial to differentiate resistant and non-resistant strains. However, taking into account that traditional processes for the identification of this pathogen are usually very slow, techniques such as PCR are applied because of their efficacy and efficiency. However, techniques such as PCR-RT have improvements that provide some advantage compared to its predecessor
\end{abstract}

Keywords: Staphylococcus aureus, MRSA, PCR, PCR-RT

1 Centro de Investigación en Alimentación y Desarrollo Hermosillo, Sonora, México Correo: patricia.palafox.mc18@estudiantes.ciad.mx

2 Centro de Investigación en Alimentación y Desarrollo Hermosillo, Sonora, México Correo: michel.palafox.mc18@estudiantes.ciad.mx

3 Centro de Investigación en Alimentación y Desarrollo Hermosillo, Sonora, MéxicoCorreo: jorge.peralta.mc18@estudiantes.ciad.mx 


\section{INTRODUCCIÓN}

Staphylococcus aureus es un coco gram positivo, aerobio facultativo relacionado a enfermedades serias en el ser humano. Debido al uso indiscriminado de antibióticos, algunas cepas han desarrollado multiresistencia, tal es el caso de las cepas $S$. aureus resistente a meticilina (SARM) [1]. Las cepas SARM son la principal causa de muerte por infecciones nosocomiales [2]. Se atribuyen alrededor de 5,400 muertes y más de un millón de pacientes hospitalizados infectados con SARM en los últimos años [3]. Las cepas definidas como SARM presentan resistencia a penicilinas sistémicas, cefalosporinas, betalactámicos, quinolonas y lincosamidas. Ésta multiresistencia a antibióticos, se le atribuye al gen mecA [4]. La identificación de este gen es determinante para diferenciar a las cepas resistentes y no resistentes.

En la actualidad, la detección de SARM puede realizarse por métodos genómicos 0 por métodos no genómicos convencionales; estos últimos tienen la ventaja de estar más al alcance de los laboratorios de microbiología convencionales[4].Sin embargo, los métodos de identificación convencionales consumen mucho tiempo y pueden dar resultados falsos positivos o falsos negativos [5]. Para una identificación más directa de SARM se llevan a cabo técnicas de amplificación genética como PCR (reacción en cadena de la polimerasa) y PCR en tiempo real utilizando genes exclusivos de $S$. aureus como: nuc y mecA [6]. La amplificación por estas metodologías se considera de los métodos más sencillos y que a la vez proporcionan mejor información en la identificación de cepas aisladas de diferentes industrias.

\section{PCR punto final y PCR en tiempo real}

La PCR punto final es una reacción enzimática que se lleva a cabo in vitro, y amplifica millones de veces una secuencia específica de ADN durante varios ciclos repetidos en los que la secuencia blanco es copiada fielmente [7]. Para ello, la reacción aprovecha la actividad de la enzima ADN polimerasa que tiene la capacidad de sintetizar naturalmente el ADN en las células [8]. Para llevar a cabo este procedimiento se utiliza una ADN Polimerasa termoestable, obtenida del Thermus aquaticus por su resistencia a altas temperaturas[9]. EI desarrollo de esta técnica ha permitido el estudio y manipulación de mejor forma al ADN, facilitando el establecimiento de protocolos experimentales en biología molecular [6].

Con el tiempo se han añadido modificaciones a esta técnica donde se han adaptado nuevas variables para la mejora del procedimiento; entre ellas se encuentra la PCR en tiempo real (RT-PCR) que es una variante de la PCR punto final, en donde la forma de cómo se detectan y analizan los productos de la amplificación es diferente [10]. El término tiempo real se refiere a la detección de los productos amplificados sucede en cada ciclo de la reacción

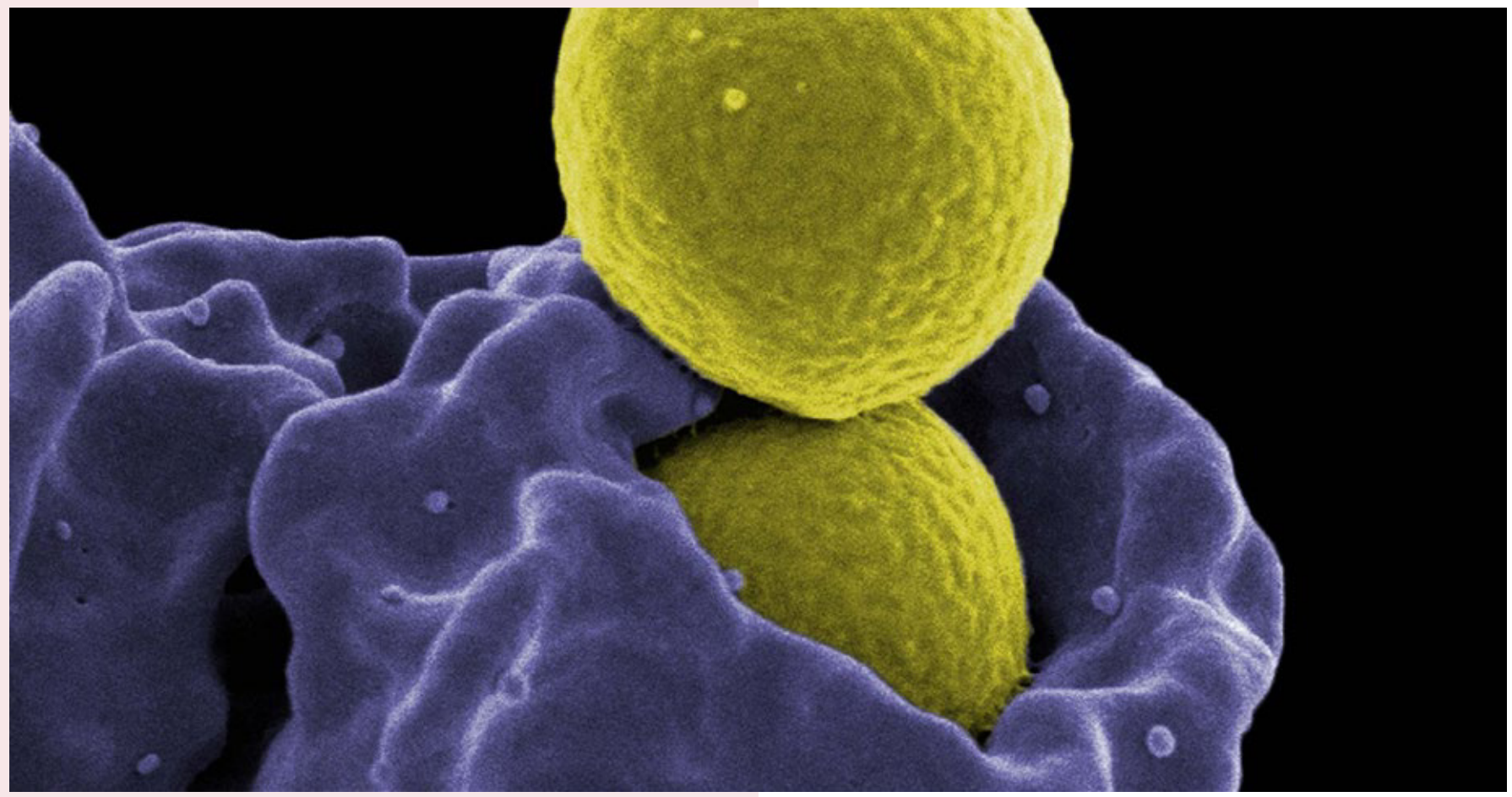




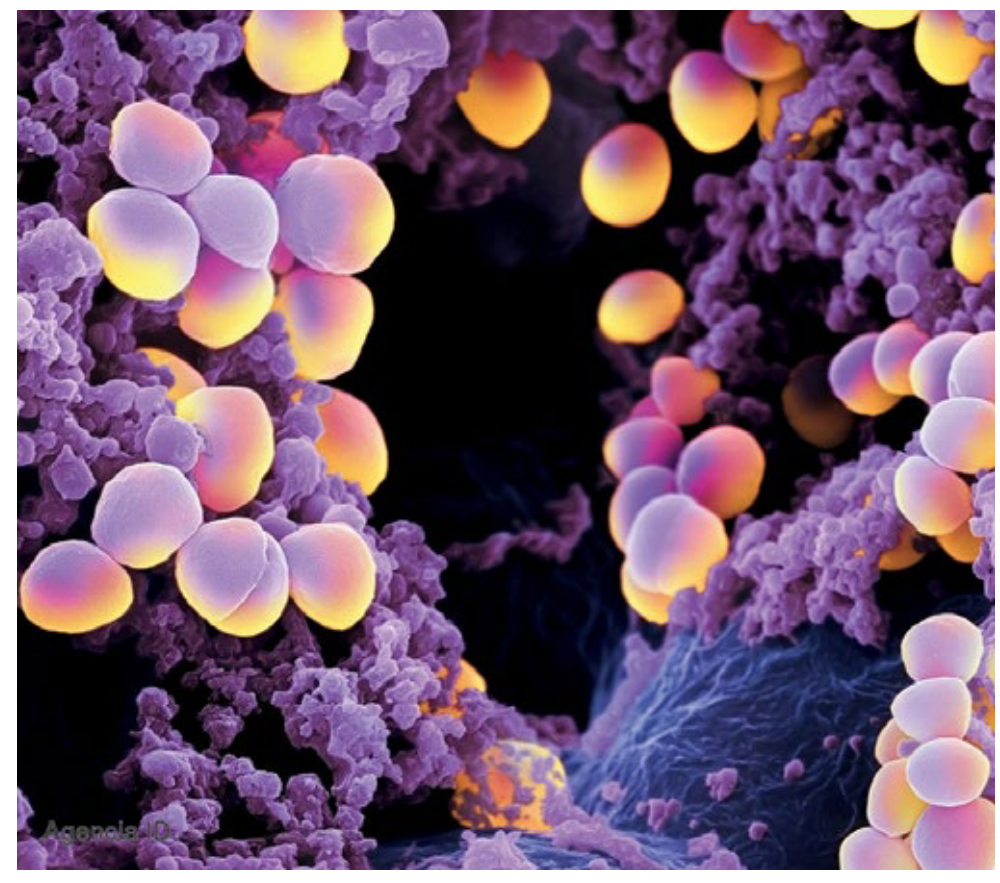

y además es posible cuantificar la cantidad de ADN en la muestra. La PCR-RT posee como ventaja que permite amplificar en una sola reacción dos o más secuencias de ADN, utilizando varias parejas de cebadores, facilitando la detección, identificación y cuantificación simultánea de distintos genes de interés [11]. Actualmente, la RTPCR es el método más sensible para detectar y cuantificar ácidos nucléicos, aun cuando se tiene poca cantidad de templado [6].A diferencia de la PCR puntual en la PCR RT la concentración de la secuencia blanco se determina por la acumulación de fluorescencia a medida que ocurre la amplificación [12]. Además, la PCR en tiempo real también incorporó la posibilidad de obtener resultados cuantitativos mediante la fluorescencia [13].

\section{Detección de SARM por PCR}

Esta técnica es utilizada comúnmente para aislados hospitalarios al hacer más eficiente el proceso de identificación reduciendo el tiempo de análisis a solo 2 horas para obtener el resultado a comparación del método tradicional que puede abarcar desde 5 a $5 \mathrm{~h} \mathrm{[14].}$ Técnicas como PCR facilitan la posibilidad de disponer en forma rápida de la susceptibilidad antimicrobiana de S. aureus, permitiendo el inicio oportuno y documentado del tratamiento con cloxacilina. Este hecho evita el uso innecesario de antibióticos como la vancomicina y favorece el control del surgimiento de resistencia a este antibacteriano en otras especies asociadas a infecciones intrahospitalarias [15].

En general si comparamos ambas técnicas ambos métodos poseen tanto ventajas como desventajas; las cuales se ejemplifican en la tabla 1 [16].

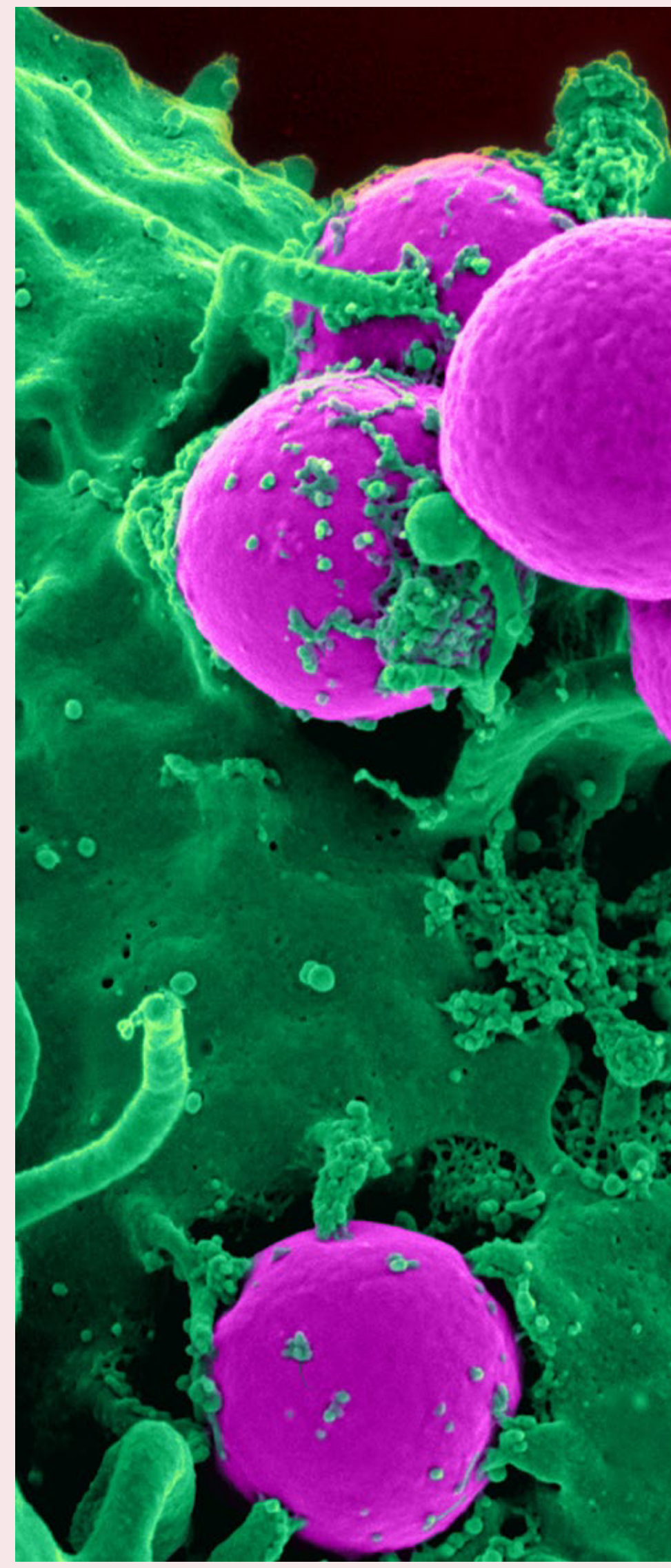




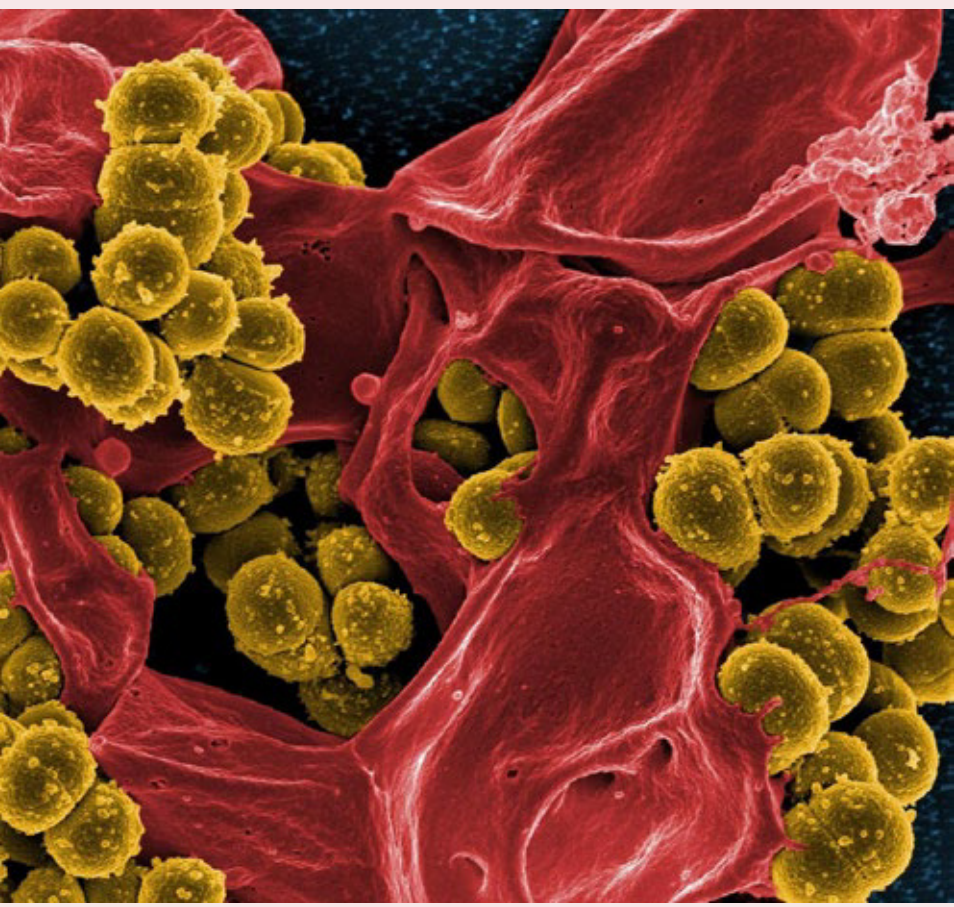

Tabla 1. Diferencias entre RCR y PCR-RT

\section{PCR}

Rango de detección estrecho

Menor sensibilidad

Menor especificidad

Costos bajos

Menor eficiencia en la reacción

Para finalizar, ambas técnicas son de las más utilizadas actualmente principalmente para la identificación de patógenos debido a su eficacia en comparación con otras técnicas moleculares.

\section{BIBLIOGRAFÍA}

[1] Figueroa , E.M. and M.D. Navarrete Prevalencia de staphylococcus aureus resistente a meticilina y caracterización del factor de virulencia leucocidina panton-valentine asociado a factores de riesgos en estudiantes de la carrera de medicina de la Universidad de las Américas. 2019, Quito: Universidad de las Américas, 2019.

[2] Wu, S., et al., Prevalence and Characterization of Food-Related Methicillin-Resistant Staphylococcus aureus (MRSA) in China. Frontiers in Microbiology, 2019. 10(304).

[3] Peralta Quito and S. Gabriela, Factores asociados a infecciones por Staphylococcus aureus resistente a la meticilina, Hospital Vicente Corral Moscoso. Cuenca, 2016-2018. 2019.

[4] Armas Fernández, A., et al., Resistencia de Staphylococcus aureus a la meticilina en aislamientos nosocomiales en un hospital provincial. Gaceta Médica Espirituana, 2015. 17: p. 80-91.

[5] Reischl, U., et al., Rapid Identification of MethicillinResistant $<$ em $>$ Staphylococcus aureus $</$ em $>$ and Simultaneous Species Confirmation Using Real-Time
Fluorescence $P C R$. Journal of Clinical Microbiology, 2000. 38(6): p. 2429-2433.

[6] Tamay de Dios, L., C. Ibarra, and C. Velasquillo, Fundamentos de la reacción en cadena de la polimerasa $(P C R)$ y de la $P C R$ en tiempo real. Investigación en discapacidad, 2013. 2(2): p. 7078.

[7] Santander, H.C., et al., ADN polimerasas bacterianas. Archivos de medicina, 2018. 14(2): p. 4

[8] Lázaro, R. and E.L. Leandro, Implementación del método de detección de adenovirus en moluscos bivalvos mediante la técnica de reacción en cadena de la polimerasa (PCR). 2017.

[9] Pedrosa Amado, A., Reacción en cadena de la polimerasa. Revista Archivo Médico de Camagüey, 1999. 3: p. 0-0.

[10] Pahissa Berga, A., Identificación, in Infecciones producidas por Staphylococcus aureus, m. ICG, Editor. 2009: Valencia, españa. p. 22.

[11] Varela-M, R.E., J.S. Arias, and L.E. Velásquez, Estandarización de una prueba múltiple de reacción en cadena de la polimerasa en tiempo real para la identificación de Angiostrongylus cantonensis, A. costaricensis y A. vasorum. Biomédica, 2018. 38: p. 111-119.

[12] Poma, H.R., et al., Comparación de la eficiencia de extracción de ácidos nucleicos utilizando distintos kits comerciales y empleando la qPCR. Efecto de las sustancias inhibidoras. Revista Argentina de Microbiología, 2012. 44(3): p. 144-149.

[13] Fusco, V., G. Blaiotta, and K. Becker, Staphylococcal Food Poisoning, in Food Safety and Preservation. 2018, Elsevier. p. 353-390.

[14] Costa, A.-M., I. Kay, and S. Palladino, Rapid detection of mecA and nuc genes in staphylococci by real-time multiplex polymerase chain reaction. Diagnostic microbiology and infectious disease, 2005. 51(1): p. 13-17.

[15] ULLOA, M.T., et al., Comparación de reacción de polimerasa en cadena, látex y antibiograma para detección de Staphylococcus aureus meticilina resistente. Revista chilena de infectología, 2001. 18: p. 255-260.

[16] Brigitte, T. and C. Chávez, Virus del papiloma humano identificados por biología molecular. Hospital Andino. Riobamba. mayo 2017-junio 2018. 2018, Universidad Nacional de Chimborazo, 2018.

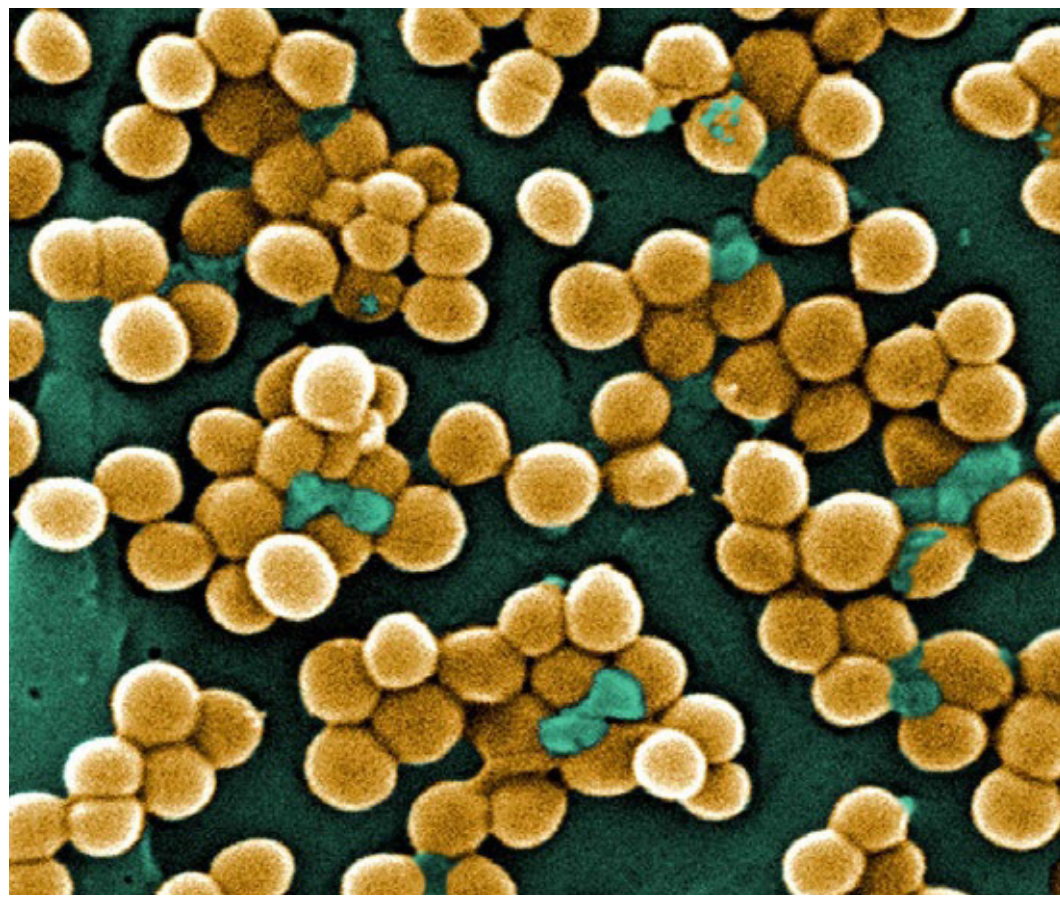

